\title{
INNOVATION POSIBILITIES IN THE FIELD OF EDUCATION AND TRAINING STAFF COMPETENCIES DEVELOPMENT MICROEXPRESIONS - „THE VOICE OF TRUTH” IN THE SOCIO-EDUCATIONAL ENVIRONMENT
}

\author{
Maria MION POP \\ Prof. PhD. candidate \\ Faculty of Psychology and Educational Sciences, \\ University of Bucharest \\ mariana.mionpop@libero.it \\ Antoaneta-Firuța TACEA \\ Lect. univ. PhD., \\ Faculty of Psychology and Educational Sciences, \\ University of Bucharest \\ ftacea@yahoo.com
}

DOI:10.5901/mjss.2014.v5n22p552

\begin{abstract}
To investigate the human being determines continuously the interest and the need to discover. Science revels specific features of human being, on how common as they are fundamental in the relational and socio-educational context. This context is mainly generated by the actual economic development. Even because this social, economic, and educational context, we aim to analyze micro expression's meanings within the context of competencies development for those who are involved in the education and training field. The objective of our approach is to demonstrate that is necessary to improve the training offers for the education and training staff innovatively fructifying one of the interesting areas of the Neuro-Linguistic Programming - micro-expressions. The adjustment of the relations between actors involved in the educational process has implications in the social sphere, in a wider context. The balance of the interaction between teacher and students affects majorly the welfare of the society. The educational atmosphere influences the student's results, the results of tomorrow professional. The training providers in the educational field don't embodied in their training offers the micro-expression issue, to recognize immediately the student's reactions. So, we intend to open the discussion about the integration of the micro-expression issue in the training programs for teachers and trainers. The relation between employer/ manager/ leader/ teacher/ trainer and the student could be seen as the relation between buyer and seller: the teacher/ trainer offers to the students his education/ training services, his competencies. The employer has to anticipate the relation between teacher and student, if he wants to change the school managed by him selves. He should offer for his students an interlocutor able to understand student's reactions - using both verbal and non-verbal language. A teacher trained to understand microexpressions is an expert. In this context, the relation between teacher and student could be seen as a contextual aspect of training, supervised by controlling the non-verbal dialogue.
\end{abstract}

Keywords: Innovation, education, training, competencies, development, micro-expressions

\section{Introduction}

The education and training staff, firstly teachers, is the main professional category always invoked when are discussed and publicized the learning results of the students. Even if the directly determination relation between the quality of the teacher professional training and the quality of the students' learning results is controversial, within the social perception at the general level, teachers are mainly responsible for students' learning results. This is the way to anticipate and foreshadow the directions of intervention for those situations from a certain context where the learning results are not satisfying at the national level. In this case is Romania. Relevant examples are those encountered during the last 4 years in case of national Baccalaureate examination or the international evaluations (TIMSS, PISA, PIRLS). 
Concluding, the priority is teacher training. For this area, because the resources are limited, and the critical issues of the wide field of the teacher training are numerous, is necessary to identify and select those aspects which lead explicitly to improve learning results. Analysis of the teacher training offers at national level, especially for initial training, but also for continuing training, revel an insignificant interest for developing interaction competencies with student as learner. In many cases this issue is a kind of topic included in the large areas of instruction theory and methodology, pedagogical communication or classroom management. In these contexts are emphasized some aspects of the learning situation structure such as: educational aims, learning content (meanings recognized by educational actors), and instruction time. The meanings of the interaction between teacher and student, the fundamental corpus of knowledge regarding the interaction competencies of the teacher have not the same importance.

If we try to imagine the educational situation as a potential authentic social context, relevant for the real life of the student in the future, especially for his future professional life, we become able to discover another key issues relevant for teacher training or educational research such as:

- $\quad$ The impact or the effects of non-verbal communication on students, at general level, and different aspects of learning - motivation, interest, observational skills, understanding, creativity, etc.;

- Useful research tools for investigation of the context - including cultural context - where the students' prior learning was structured; Useful research tools for investigation of the professional context where the student, at the end of the school, will use his learning results; this is the vocational education and training component, even during those periods of education which are not explicitly allocated for vocational education and training (VET); To fundament the learning offers on evidences provided by students themselves as beneficiaries of their teachers services (feedback perception),

Etc.

Of course, these aspects could be completed or shaded with specific elements in case of designing the training offers for those who intend to become trainers in the field of education and training.

One from the previous presented aspects could be considered a specific key issue for improvement the teacher training and trainer of trainers offers in the meantime. This is the micro expression field as:

a. Knowledge area significant for the field of science of education;

b. Vocational competencies that could be achieved by teachers in relation with micro expression;

c. Possible relations/ dimensions of the micro expression field, in educational context, to be investigated using educational research tools.

These areas could be completed or developed and could become relevant for the field of theory or the practice of educational sciences. More than these we can talk about the possibility to extend them to other fields of activity/ occupational area, in accordance with the specification of their particularities.

As a relevant area for the educational sciences field the micro expression embody knowledge about: practical and theoretical contributions to develop the micro expression domain (the epistemological identity of the domain), micro expressions types - desciption, ways to identify/ decode, causality, micro expressions in the human behavior context, micro expressions in the social interactions' context, educational context: classroom - teaching, students counseling, remedial education, pupils with special educational needs approach, learning in non-formal and informal contexts, educational management, etc.

With regard to the vocational competencies related within the micro expressions field that can be achieved by teachers, like the communication area in general, we'll focus on two dimensions: messages reception, decoding, and expression. After reception and decoding, for teachers is crucial how they use the decoded message following educational aims, in accordance with existing good practices and research results. Micro expressions become also significant for the teaching process itself structured as teaching, learning, and evaluation.

There are some examples of possible competencies to be achieved by teachers who value the micro expressions:

The complex understanding of the students' answers/ results, in accordance with the verbal/ written, and non-verbal meanings;

Providing feedback for students in accordance with their reactions expressed also through micro expressions; 
- $\quad$ Consistent, systematic, and continue observation of the students' micro expressions during the learning activities, as a mean of improve the quality of these activities;

- $\quad$ Expressing coherent messages for students as their verbal and non-verbal content (including the message communicated through micro expressions);

Supporting students to be aware of the messages expressed through micro expressions;

- $\quad$ Individualizing (personalizing) the learning offers depending on the students' micro expressions;

- $\quad$ Improving the managerial team' interaction competencies using micro expressions;

- etc.

These competencies could be diversified depending on different contexts or identified needs and could be converted in purposes for teachers training programs.

In the field of micro expressions could generate interest for educational research aspects such as:

- $\quad$ The types of micro expressions that appear often in students' reactions, in the context of facing different learning contents, at different levels of complexity;

The types of micro expressions that appear often in students' reactions, in the context of receiving different types of feedback - positive or negative;

The types of micro expressions that appear often in students' reactions, in the context of receiving different messages form teacher - learning tasks, evaluation tasks, evaluative judgments, appreciations about their behavior, coherent or incoherent verbal and non-verbal messages and so on;

- $\quad$ Types of teachers' micro expressions that determine the improvement or not the level of performance in relation with learning results,

etc.

Obviously there are more significant aspects for difficult situations that could be inquired in complex, particular contexts, and approached through action research or could be structured study cases having micro expressions as predictor. Also we can imagine in a research enterprise how to correlates micro expressions with some other emotional expressions, detailed through indicators such as: dermal humidity, heart rhythm, respiratory rhythm, etc. The results of this kind of research could be considered useful evidences for the education and training field, but also for other occupational fields, at an extended level.

Returning at the necessity of improving and diversifying teacher training offers, in order to increase the social and vocational relevance of the teachers' interventions on their students, we can continuously identify issues like micro expressions that skill them in accordance with the existing labor markets' requirements - competitiveness, professionalization for regulated occupations, high professional performances that assure the learning achievements' transfer, etc.

\section{Bibliographical references}

Guskey, Thomas R. (2000). Evaluating professional development. California: CORWIN PRESS, INC. Morris, D. (2002). PEOPLEWATCHING (ed. 20). London: VINTAGE BOOKS.

Potolea, D.; Neacșu, l.; lucu, R. B.; Pânișoară, I.-O. (Coord.) (2008). Pregătirea psihopedagogică. Manual pentru definitivat și gradul didactic II. Iași: POLIROM.

Wezowski, P.; Wezowski, K. (New Vision - Center for Body Language). Micro Expressions Training Videos. On line training course. Accessed during April-June 2014, at:

http://www.microexpressionstrainingvideos.com/members/\#sthash.XUAe2aoH.dpuf 